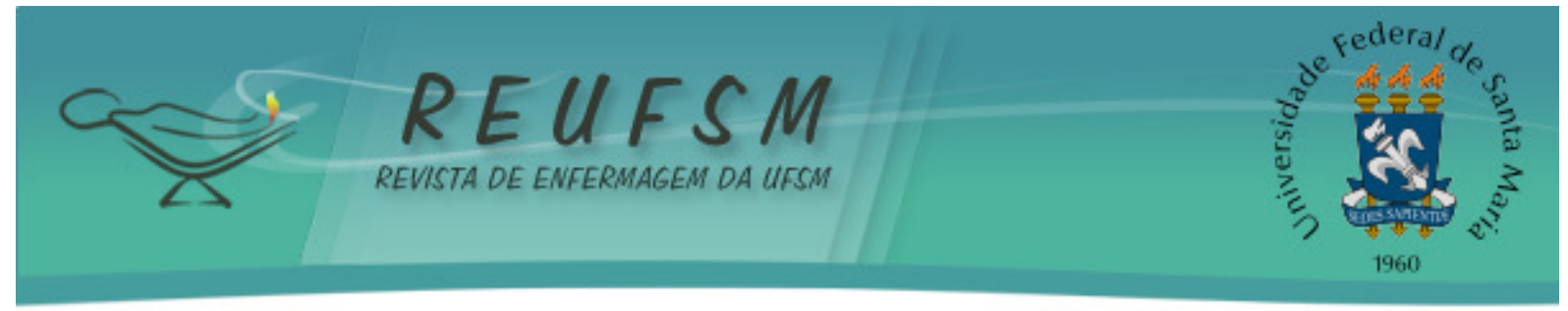

ARTIGO ORIGINAL

\title{
EQUIPAMENTOS DE PROTEÇÃO INDIVIDUAL: A PERSPECTIVA DE TRABALHADORES QUE SOFRERAM QUEIMADURAS NO TRABALHO
}

\section{PERSONAL PROTECTIVE EQUIPMENT: THE PERSPECTIVE OF WORKERS WHO SUFFERED BURNS AT WORK}

\section{EQUIPOS DE PROTECCIÓN INDIVIDUAL: LA PERSPECTIVA DE TRABAJADORES QUE SUFRIERON QUEMADURAS EN EL TRABAJO}

\author{
Caroline Lemos Martins ${ }^{1}$ \\ Michelle Barboza Jacondino ${ }^{2}$ \\ Liliana Antoniolli ${ }^{3}$ \\ Dione Lima Braz ${ }^{4}$ \\ Jéssica Bazzan ${ }^{5}$ \\ Maria Elena Echevarría-Guanilo ${ }^{6}$
}

Doi: $10.5902 / 2179769211060$

RESUMO: Objetivo: conhecer, na perspectiva dos trabalhadores, a importância do uso de equipamentos de proteção individual para prevenção de acidentes de trabalho por queimadura. Método: estudo de abordagem qualitativa, realizado em um Centro de Referência em Assistência a Queimados, com seis trabalhadores que sofreram queimaduras decorrentes de acidentes de trabalho. A coleta de dados ocorreu no período de junho a outubro de 2012, por meio de entrevista semiestruturada. Os dados obtidos foram submetidos à análise de conteúdo. Resultados: a maioria reconhece a importância do uso de equipamentos de proteção individual adequados aos riscos presentes no ambiente de trabalho; porém, a falta ou o uso inadequado podem ter favorecido a ocorrência de queimaduras ocupacionais. Considerações finais: empregadores e profissionais de enfermagem necessitam investir na capacitação e treinamento dos trabalhadores para o uso adequado dos equipamentos de proteção individual de forma a possibilitar um ambiente de trabalho mais seguro.

Descritores: Acidentes de trabalho; Queimaduras; Equipamentos de proteção; Saúde do trabalhador; Enfermagem.

ABSTRACT: Aim: to get to know the importance of the use of personal protective equipment in the prevention of burn accidents at work according to employees. Method: a qualitative study, carried out at Referral Center for Burns Care, involving six workers who were victims of occupational burn accidents. The data collection took place between June

\footnotetext{
${ }^{1}$ Enfermeira. Mestre em Ciências pelo Programa de Pós-Graduação em Enfermagem da Universidade Federal de Pelotas, Pelotas, RS, Brasil. E-mail: kroline_lemos@hotmail.com

2 Enfermeira. Doutoranda em Enfermagem pelo Programa de Pós-Graduação em Enfermagem da UFPel, Pelotas, RS, Brasil. E-mail: michellejacondino@gmail.com

3 Acadêmica de Enfermagem da Faculdade de Enfermagem da UFPel, Pelotas, RS, Brasil. E-mail: l.antoniolli@hotmail.com

${ }^{4}$ Enfermeira. Mestranda em Ciências pelo Programa de Pós-Graduação em Enfermagem da UFPel, Pelotas, RS, Brasil. E-mail: dionepel@bol.com.br

5 Acadêmica de Enfermagem da Faculdade de Enfermagem da UFPel, Pelotas, RS, Brasil. E-mail: jessica_bazzan@hotmail.com

${ }^{6}$ Enfermeira. Doutora em Ciências pela Escola de Enfermagem de Ribeirão Preto da Universidade de São Paulo. Docente do Programa de Pós-Graduação em Enfermagem da UFPel, Pelotas, RS, Brasil. E-mail: elena_meeg@hotmail.com
} 


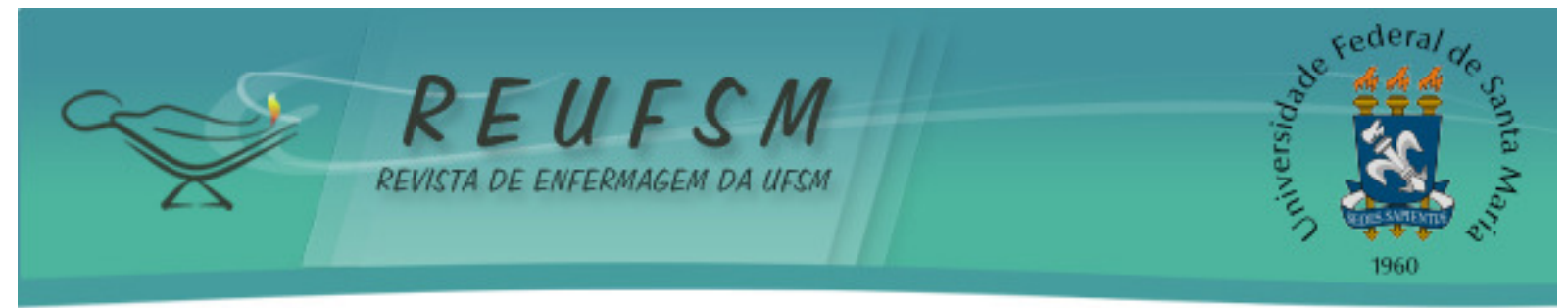

and October 2012 through semi-structured interviews. The collected data were processed through content analysis. Results: the majority acknowledges the importance of using personal protective equipment that is appropriate to the occupational risks; nevertheless, the lack of or the inappropriate use may have favored the occurrence of occupational burns. Conclusions: employers and nursing professionals need to invest in professional training for the proper use of personal protective equipment with a view to achieving $a$ safer work environment.

Descriptors: Accidents occupational; Burns; Protective devices; Occupational health; Nursing.

RESUMEN: Objetivo: conocer, desde la perspectiva de los trabajadores, la importancia del uso de equipos de protección personal para prevención de accidentes de trabajo con quemadura. Método: estudio con enfoque cualitativo, realizado en un Centro de Referencia en Atención al Quemado, con seis trabajadores que sufrieron quemaduras originadas por accidentes de trabajo. Los datos fueron recogidos de junio a octubre del 2012, mediante entrevista semiestructurada. Los datos obtenidos fueron sometidos al análisis de contenido. Resultados: la mayoría reconoce la importancia del uso de equipos de protección personal apropiado a los riesgos presentes en el lugar de trabajo; sin embargo, la falta o el uso inadecuado puede haber favorecido la ocurrencia de quemaduras laborales. Consideraciones finales: los empleadores y los profesionales de enfermería necesitan investir en la capacitación de trabajadores para el uso adecuado del equipo de protección personal, de manera a posibilitar un entorno de trabajo más seguro.

Descriptores: Accidentes de trabajo; Quemaduras; Equipos de seguridad; Salud laboral; Enfermería.

\section{INTRODUÇÃO}

0 uso de Equipamentos de Proteção Individual (EPI) confere proteção à integridade física e psíquica das pessoas durante a manipulação dos instrumentais de trabalho e contribui para prevenção de acidentes. Os ambientes de trabalho, pela natureza das atividades, expõem os trabalhadores a riscos e perigos, os quais podem ser minimizados ou eliminados se houver utilização de EPI. ${ }^{1}$

Estudo de revisão de literatura ${ }^{2}$ identificou que, independentemente do ambiente de trabalho, os trabalhadores são expostos a riscos para doenças e acidentes ocupacionais. Adotar medidas de prevenção é, portanto, fundamental, sendo essencial o emprego de práticas seguras para reduzir os riscos de acidentes. ${ }^{2-3}$

O EPI (por exemplo, máscaras, avental, óculos de proteção e luvas) é definido como o dispositivo individual usado pelo trabalhador para proteção durante atividades de trabalho que podem ameaçar sua segurança e saúde, porém estes equipamentos necessitam estar adequados aos riscos e manter as características de conservação e funcionamento. ${ }^{4}$

Entre os riscos presentes no ambiente físico de trabalho, destacam-se os de natureza química, física, biológica, mecânica, ergonômica, psicossocial, e outros relacionados à energia e à condução de veículos, que podem incapacitar ou levar trabalhadores à morte. ${ }^{1}$ Ao analisar as principais causas de queimaduras ocupacionais, observa-se que são decorrentes principalmente de agentes térmicos, elétricos e químicos. ${ }^{5}$

Algumas ocupações (em meio industrial, por exemplo), expõem os trabalhadores à ocorrência de queimaduras, especialmente pela manipulação de líquidos quentes, eletricidade e equipamentos. ${ }^{5}$

Investigação ${ }^{6}$ realizada nos serviços de urgência e emergência de 23 capitais e do Distrito Federal brasileiro, no ano de 2009, evidenciou que dos 761 atendimentos a 


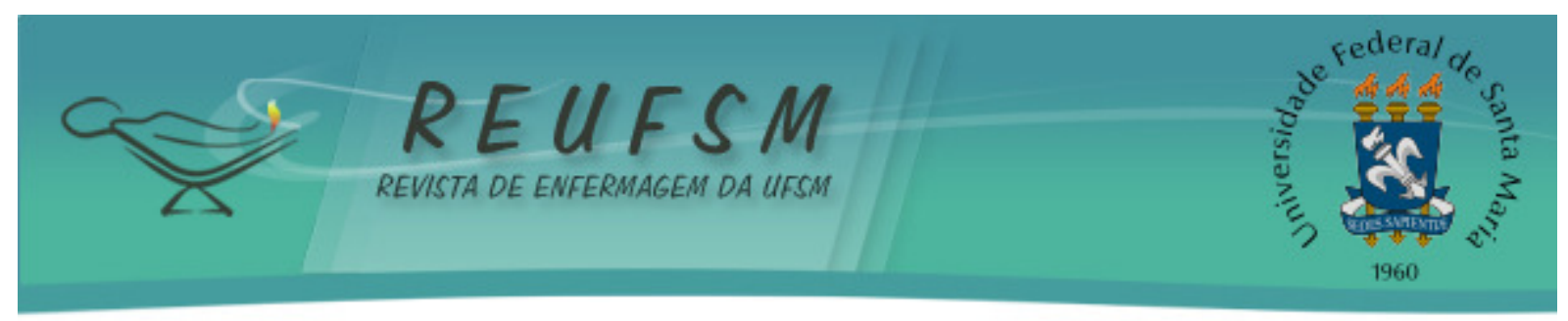

indivíduos queimados, aproximadamente um terço decorreu de agravos desencadeados no ambiente de trabalho. Os adultos jovens, entre 20 e 29 anos de idade, foram os principais acometidos, sendo o comércio, serviços, indústria e construção, os locais onde ocorreu a maior parte das queimaduras.

A capacitação, por meio de treinamentos, dos trabalhadores para identificação dos riscos e utilização adequada de EPI pode fazer com que desenvolvam um sentimento de compromisso e responsabilidade para com a sua própria segurança ${ }^{7}$ e adotem estratégias de enfrentamento frente aos riscos, permitindo manter o processo de produção e evitando agravos à saúde. ${ }^{8}$

A realização da presente investigação justifica-se pela carência de estudos nacionais que abordem o uso dos $\mathrm{EPI}^{3}$ para prevenção das queimaduras ocupacionais. ${ }^{6}$ Além disso, pesquisas de abordagem qualitativa a respeito do uso destes equipamentos contribuem para compreensão de aspectos que afetam a saúde dos trabalhadores no ambiente de trabalho ${ }^{3}$ e podem auxiliar na identificação de informações relevantes para prevenção de acidentes.

Pelo exposto, o desenvolvimento do presente estudo norteou-se pela questão: qual a perspectiva do trabalhador em relação ao uso de equipamentos de proteção individual na prevenção de acidentes de trabalho por queimaduras? Como objetivo, definiu-se conhecer, na perspectiva dos trabalhadores, a importância do uso de equipamentos de proteção individual para prevenção de acidentes de trabalho por queimaduras.

\section{MÉTODO}

Estudo de abordagem qualitativa, do tipo exploratório descritivo, realizado em um Centro de Referência a Queimados da região Sul do Brasil. O cenário de estudo caracterizase por ser uma unidade de internação de média complexidade. Conta com oito leitos de internação para o atendimento multiprofissional de pacientes adultos provenientes, em sua maioria, do Sistema Único de Saúde (SUS) e do Estado do Rio Grande do Sul, Brasil.

O projeto obteve aprovação do Comitê de Ética em Pesquisa da Associação de Caridade Santa Casa de Rio Grande (Protocolo $n^{\circ}$ 004/2012), tendo atendido aos padrões éticos exigidos. ${ }^{9}$

Para seleção dos participantes foram adotados os critérios: ser maior de 18 anos de idade; ter sofrido queimaduras durante acidentes de trabalho e recebido atendimento hospitalar no Centro de Referência, de junho a outubro de 2012, independentemente do sexo e das características clínicas apresentadas (por exemplo, agente etiológico, extensão e grau da lesão); ser capaz de se comunicar em português; aceitar participar do estudo; assinar o termo de consentimento livre e esclarecido e estar prestes a receber alta hospitalar.

Os sujeitos foram identificados por meio dos prontuários da referida unidade e, próximo à alta hospitalar, foram convidados a participar do estudo. As entrevistas ocorreram no período de junho a outubro de 2012, de maneira individual e em ambiente privativo. No intuito de garantir o anonimato dos participantes, os mesmos foram identificados pela letra "E" de "Entrevistado", seguida da numeração de realização das entrevistas (Exemplos: E1, E2).

A coleta de dados foi realizada em duas etapas: Primeira etapa - Preenchimento de informações sociodemográficas e clínicas por meio de informações coletadas diretamente com os participantes (sexo, idade, cor/raça, estado civil, escolaridade, ocupação e vínculo de trabalho) e consulta aos prontuários (superfície corporal queimada, região do corpo acometida e agente etiológico); Segunda etapa - Entrevista 


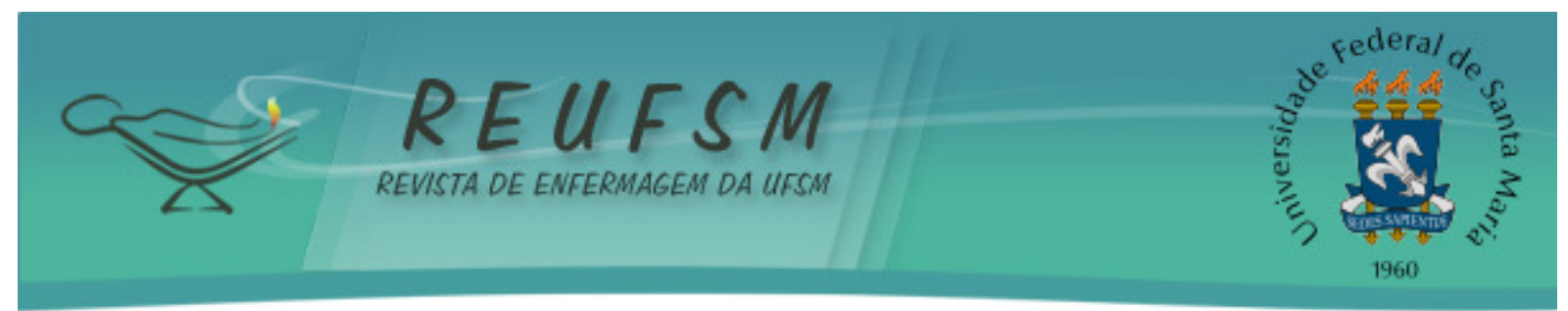

semiestruturada, com questões a respeito da manipulação de agentes térmicos, uso de EPI e riscos presentes em seu ambiente de trabalho.

As entrevistas foram gravadas e transcritas posteriormente. Para análise das informações obtidas, elegeu-se a análise de conteúdo, seguindo os passos propostos: Préanálise, Exploração do material e Tratamento dos resultados obtidos e interpretação. ${ }^{10} \mathrm{~A}$ pré-analise envolveu a organização do conteúdo das entrevistas e exploração sistemática das informações por meio de leitura flutuante e a constituição do corpus. O corpus foi submetido às regras da exaustividade, representatividade, homogeneidade e pertinência dos conteúdos expressos nas entrevistas. ${ }^{10}$

Durante a Exploração do Material, as informações foram codificadas e os recortes das falas agrupados e categorizados segundo o objetivo do estudo. A última etapa consistiu na interpretação dos recortes das falas de forma que pudessem ser significativos e válidos, permitindo o levantamento de inferências acerca da perspectiva dos trabalhadores em relação ao uso de EPI na prevenção de acidentes de trabalho por queimaduras. ${ }^{10}$

\section{RESULTADOS E DISCUSSÃO}

As entrevistas possibilitaram identificar alguns fatores que contribuíram para ocorrência de queimaduras, tais como manipulação de agentes térmicos, não utilização de EPI e os riscos presentes nos ambientes de trabalho. Tais informações subsidiaram a construção de duas categorias, as quais são descritas a seguir, precedidas da caracterização dos sujeitos do estudo.

\section{Caracterização dos sujeitos do estudo}

Participaram do estudo seis sujeitos que atenderam aos critérios de inclusão, sendo todos do sexo masculino, com idades entre 21 e 40 anos; quatro consideraram-se brancos e dois negros; quatro casados, com número de filhos entre zero e três. Quatro trabalhadores tinham o ensino médio completo, um o ensino fundamental completo e um incompleto. Autores assinalam a predominância de acidentes de trabalho por queimaduras no sexo masculino, adultos jovens ${ }^{5,6,11}$ e com menor nível de instrução. ${ }^{6}$

No que diz respeito às ocupações, dois participantes se denominaram soldadores, um eletricista, um operador de fornalha, um motorista de caminhão e um padeiro. Atuavam no serviço entre seis meses e dez anos. Quatro trabalhadores possuíam vínculo empregatício formal e, dois, informal. Autores ${ }^{12}$ referem que a precarização das condições e vínculos de trabalho descaracterizam as relações interpessoais e contribuem para a invisibilidade do trabalho real.

Em relação à gravidade do acidente e região do corpo acometida, cinco participantes apresentaram queimaduras com predomínio de segundo e terceiro grau, com superfície corporal queimada entre seis e 35\%. A face, a região cervical, tronco anteroposterior, abdômen, membros superiores e inferiores foram as regiões mais atingidas, corroborando os resultados de pesquisa já realizada. ${ }^{11}$ Dos seis trabalhadores, três tiveram queimaduras por fogo direto, dois por explosão e um por eletricidade. Queimaduras ocupacionais por eletricidade e fogo também foram observadas em estudos anteriores. ${ }^{5,6}$

\section{Características dos ambientes de trabalho e percepção de risco}

As características dos ambientes de atuação podem gerar ou intensificar o medo entre os trabalhadores pela presença dos riscos de origem física, química, elétrica e da organização do espaço laboral, os quais comprometem a saúde e acarretam acidentes ou 


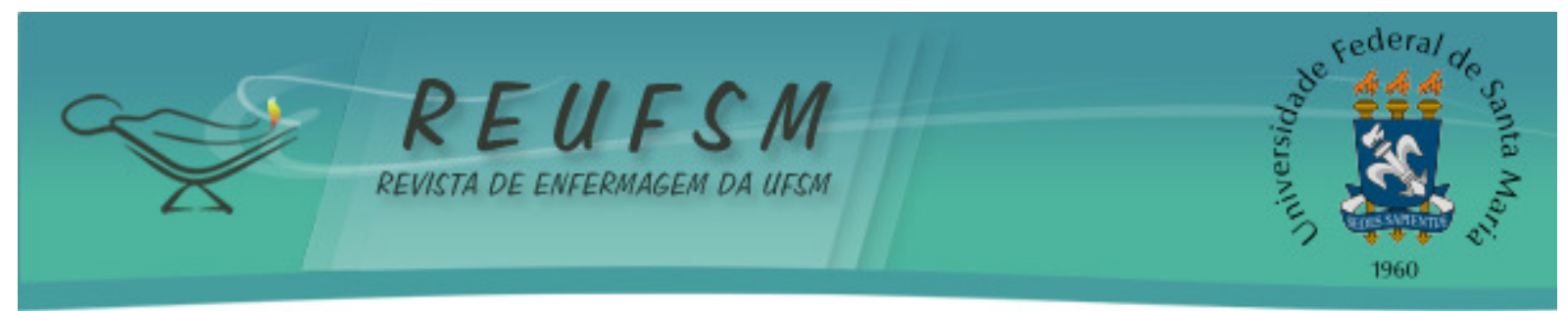

patologias do trabalho. ${ }^{1}$ Sob essa ótica, os trabalhadores relataram características dos seus cenários de trabalho:

[...] o ambiente, não é um ambiente limpo. [...] é sujeira, [...] é muita poeira. $O$ pó é perigoso. [...] É muito barulho, porque é muita máquina. [...] E cansativo, é pesado, é um calor quase insuportável. Não é fácil! (E4)

A atividade não é perigosa, o ambiente é perigoso. Você tem que usar o cinto, porque de uma altura daquelas, não tem escapatória, se você cair, já era. Todo ambiente de metalúrgica é muito perigoso. (E6)

Observa-se que os sujeitos percebem os riscos de origem física (queda e ruído) e química (pó e sujeira) no ambiente de trabalho, os quais podem favorecer a ocorrência de acidentes e agravos à saúde do trabalhador.

Considerando que os riscos podem fazer parte do ambiente de trabalho, os trabalhadores necessitam adotar estratégias para minimizá-los, sendo uma delas o uso cotidiano de EPI. $^{7}$ Nesse sentido, autores ${ }^{13}$ mencionam que, ao reconhecerem aspectos como o ruído excessivo proveniente do ambiente, os trabalhadores tendem a minimizar o desconforto, por meio do uso de protetores auriculares, por exemplo. Assim, compreendese que, além de encontrarem estratégias individuais e/ou coletivas para superar alguns incômodos advindos do ambiente laboral, os trabalhadores têm a obrigação de fazer o uso adequado destes EPI. A construção do mapa de riscos, prevista pela NR 05, a qual também é uma obrigação legal para as empresas, deve ser realizada em conjunto por empregados e empregadores e representa um potencial auxílio na correta identificação dos riscos e na eliminação e controle dos problemas detectados. ${ }^{14}$

A manipulação de altas temperaturas provenientes dos instrumentos de trabalho também pode ser considerada uma atividade de risco para o sujeito. 0 calor originário da estrutura dos instrumentos de trabalho e da ambiência contribuem para potencializar o perigo e os riscos de ocorrência de traumas térmicos. ${ }^{1}$ Esta constatação pode ser identificada nas falas dos participantes:

[...] são temperaturas altas, [...] são fórmulas que pedem bastante caloria. Trabalho com uma caloria de 700 graus. (E3)

Ele (forno à lenha) atinge a temperatura de até 300 graus. [...] 0 pão Frances, por exemplo, a temperatura ideal para assar é 200 graus. [...] Já, o pão Suíço [...] a temperatura é menos, [...] é 150 graus. Olha a diferença de temperatura de uma massa para outra de pão. (E2)

[...] o motor, caminhão funcionando, o calor do asfalto, você sente ao ficar no redor do caminhão. O motor do caminhão trabalha em 95 graus e mais o calor do dia. [...] lá dentro do tanque deveria estar cem graus. (E5)

Ao refletir sobre as temperaturas relatadas pelos trabalhadores, percebe-se exposição aos riscos e às situações que podem favorecer a ocorrência de traumas térmicos. O manuseio de altas temperaturas por estes sujeitos faz parte de suas atividades diárias. 


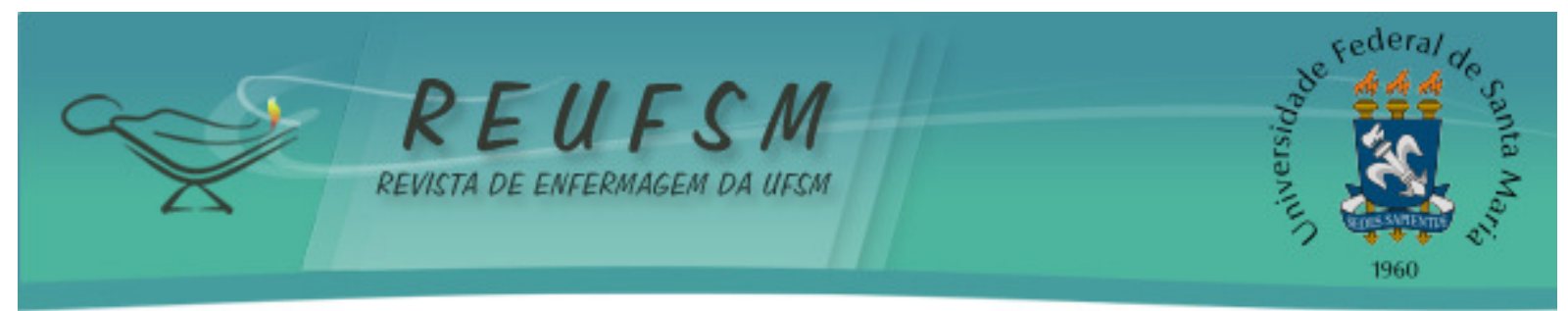

Estudo realizado em uma indústria calçadista demonstrou que a maioria dos trabalhadores possuía uma visão parcial dos riscos presentes no processo de trabalho, sendo necessário que medidas de segurança fossem implementadas para reduzir ou evitar sua exposição. ${ }^{8}$

O calor excessivo proveniente dos instrumentos de trabalho constitui uma situação desfavorável para os trabalhadores, pois aquece o ambiente e gera desconforto físico. ${ }^{15}$ Assim, o trabalhador pode tornar-se suscetível a acidentes, uma vez que, na intenção de aliviar seu desconforto, pode optar por não utilizar os EPI ou retirá-los, ainda que por breves momentos. $^{7-8}$

\section{Equipamentos de Proteção Individual para prevenção de acidentes de trabalho por queimaduras}

O uso de EPI precisa estar adequado às características das atividades realizadas pelos trabalhadores e aos riscos presentes no ambiente de trabalho e, dependendo das atividades desempenhadas, podem apresentar orientações comuns de utilização ou particularidades em função da especificidade do trabalho desenvolvido. ${ }^{4}$ Desta forma, atividades de trabalho que envolvem, por exemplo, a manipulação de agentes com potencial de ocasionar queimaduras requerem, principalmente, vestuário de proteção, mantas isolantes, óculos e luvas pelos trabalhadores. ${ }^{5}$

A utilização de EPI e de equipamentos de proteção coletiva (EPC) visa à manutenção de um ambiente seguro ${ }^{4}$ e, portanto, são identificados como subsídios para proteção dos trabalhadores frente aos riscos de acidentes e para preservação da saúde durante as atividades laborais. Observa-se alguns trechos de falas nesse sentido:

Você entrou na fábrica, teu EPI é necessário. [...] Uniforme comum, camiseta antiácida, calça, botina, óculos, protetor auricular, abafador, capacete [...]. É padrão da empresa, estando lá, tem que estar usando sempre. [...] Independente das funções que você for fazer, não pode retirar nunca. (E3)

[...] luva curta, capacete, óculos, protetor auricular, [...] usamos máscara [...] a roupa da firma, calça e jaleco. Essa é a roupa. [...] se a gente vai cortar um ferro com uma lixadeira e estiver sem óculos, ele (técnico de segurança) vai lá, avisa ou dá uma advertência [...]. Tudo que for de segurança tem que usar. (E4)

A gente usa uma máscara que protege o rosto para não inalar fungos metálicos. [...] protetor auricular, óculos [...]. Nós usamos bota, uma perneira que vem até aqui no meio da canela, [...] avental e um blusão por cima. [...] O soldador tem que usar luva, porque é uma luva de alta temperatura, [...] você trabalha muito perto do fogo, então, ela aguenta a temperatura. [...] Nossa proteção é braço e abdômen [...] o principal a proteger é essa parte. (E6)

Os depoimentos revelaram que os trabalhadores identificam a utilização de EPI para sua proteção. Sabe-se que diversos riscos e perigos permeiam a relação trabalhadorambiente e, por considerarem o cotidiano de trabalho perigoso, os sujeitos e suas empresas utilizam equipamentos de proteção..$^{7-8,15}$ Assim, estes trabalhadores verbalizam a percepção de risco para doença, acidentes de trabalho e o domínio do conhecimento sobre 


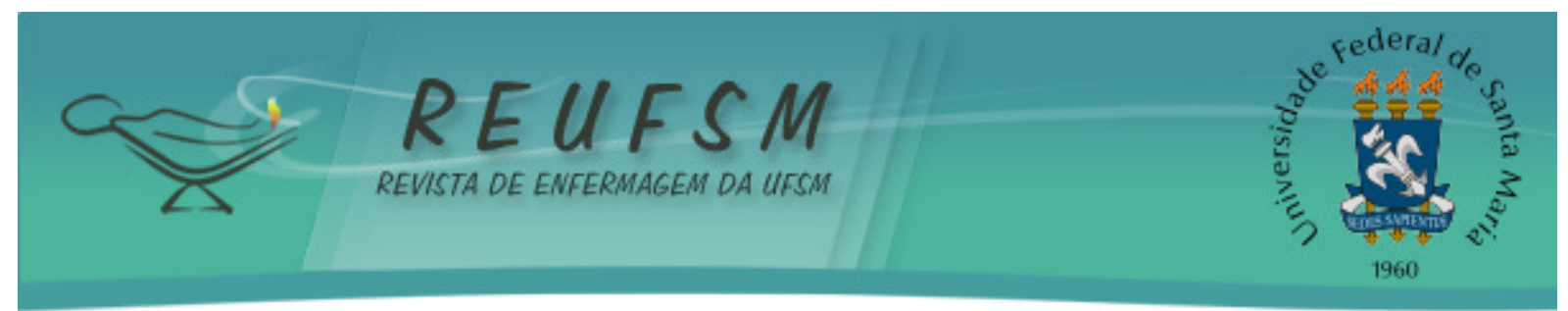

métodos de proteção para evitar eventos indesejáveis. Entretanto, embora reconheçam quais EPI são necessários para realização de suas atividades, questiona-se a possibilidade de trabalhar nestes ambientes com todos estes equipamentos de proteção, uma vez que os materiais utilizados em sua fabricação, na maioria das vezes, dificultam a locomoção e a movimentação adequada/eficiente destes indivíduos.

Destaca-se que estes dispositivos só conferem proteção ao trabalhador se usados de forma adequada e quando mantidas as características de conservação e funcionamento. ${ }^{4}$ Assim, a utilização de EPI só possibilita resultado efetivo quando associada a medidas de proteção coletiva, em atividades eventuais ou emergenciais, e no caso de exposição do trabalhador a perigos físicos, químicos, mecânicos e ergonômicos, por um breve período. ${ }^{4}$

É de responsabilidade do empregador e dos Serviços Especializados em Engenharia de Segurança e Medicina do Trabalho analisar os riscos e perigos presentes nos processos de produção, bem como fornecer aos trabalhadores EPI adequados ao tipo de atividade por eles desenvolvida, incentivando o uso ${ }^{4,8}$ em prol da conformação de um ambiente de trabalho seguro, com menor possibilidade de ocorrência de acidentes.

Cabe destacar que as empresas devem cumprir o que determinam as leis relativas à segurança e medicina no trabalho e precisam atuar na manutenção da saúde dos trabalhadores.

Nas instituições empregadoras, embora sejam disponibilizados EPI adequados aos riscos presentes no ambiente, os trabalhadores encontram dificuldades de adaptação e manuseio dos instrumentais de trabalho. Assim, mesmo aderindo ao uso dos equipamentos, alguns mencionam ocorrência prévia de danos por acidentes, embora reconheçam a importância do uso destes equipamentos para autoproteção e prevenção de novos agravos. ${ }^{15}$

Diversas instituições utilizam EPI como parte das ações e condutas que conferem sentimentos de segurança e percepção de menor risco aos trabalhadores durante o processo de produção. Entretanto, a adoção dos mesmos não pode estar restrita à sua entrega, a qual, em algumas situações, ainda é feita de forma inadequada, sem prévio treinamento ou fiscalização de uso.

É importante destacar que, embora os trabalhadores reconheçam os benefícios dos EPI para sua saúde, sabem que seu uso nem sempre impede a ocorrência de acidentes de trabalho, especialmente em locais definidos como perigosos. ${ }^{16}$ Nessa perspectiva, os sujeitos mencionaram a falta ou a ineficácia dos EPI como responsáveis por seus traumas térmicos:

Estava usando todos os equipamentos [...] luva, capacete, óculos, [...] roupa antichama. [...] Como é alta tensão, não tem controle, uma roupa que proteja totalmente. (E1)

No rosto a gente não usa (EPI). [...] Você usa luvas, [...] chapeuzinho para não cair cabelo nas coisas, [...] máscara, para cobrir o nariz e a boca. [...] A gente não usa óculos de proteção. (E2)

Não existe proteção em si, não é um soldador que bota capa. São coisas de momento, às vezes, o caminhão morre. [...] eu sei que não tem proteção [...] como é que eu vou esperar, vou lá trocar de roupa, para arrumar uma "coisinha" que é simples. Você acaba se envolvendo, demora um tempo, então, você não troca de roupa e bota proteção. (E5)

[...] tem a camisa da empresa, que é o EPI, só que antes dessa, eu estava usando uma camisa [...] tipo um plástico [...] ela é maior um 


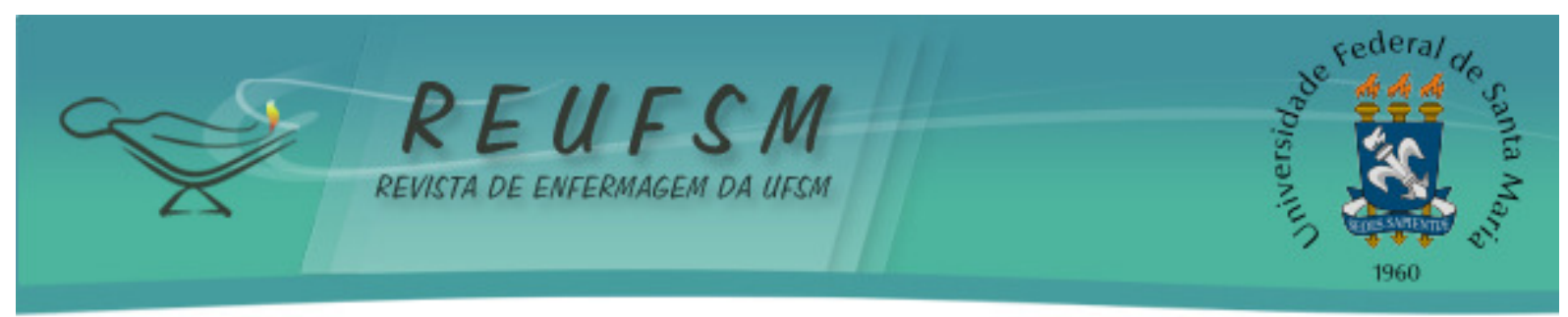

pouco que a do serviço, porque me incomoda ficar só com uma camisa. (E6)

Ao ser questionado a respeito do uso de EPI no momento do acidente, um dos entrevistados (E1) enfatizou que os mesmos, apesar de utilizados corretamente, não foram suficientes para protegê-lo da descarga elétrica ( 23 mil voltz). Em casos como este, além da utilização de EPI, que favorece a realização de um trabalho seguro, é imprescindível adotar medidas de proteção coletiva, tais como desligar a energia elétrica do local ou suspender as atividades quando identificado algum risco. ${ }^{17}$

No caso de outro trabalhador (E6), nota-se que, mesmo utilizando os EPI adequados à atividade desenvolvida, ele optou por também utilizar uma camisa comum, sobreposta ao EPI, o que pode ter favorecido a ocorrência de sua queimadura. A adaptação dos EPI também foi relatada em estudo anterior, ${ }^{16}$ quando os trabalhadores mencionaram improvisar os EPI para suportar o intenso ritmo de trabalho.

A particularidade de algumas atividades ou funções desenvolvidas pelos trabalhadores torna inadequado ou insuficiente o uso de certos equipamentos de proteção. Os trabalhadores aumentam a exposição aos riscos ao negligenciarem sua proteção ou descumprirem as regras de segurança. ${ }^{7,16}$

A Norma Regulamentadora NR-6, que dispõe sobre o uso de EPI, estabelece que todo funcionário submetido a agentes térmicos necessita utilizar EPI contra os riscos de origem térmica (óculos, protetor facial, vestimentas, calçados e luvas, por exemplo). ${ }^{4} \mathrm{O}$ não reconhecimento do trabalhador acerca da importância dos equipamentos de proteção pode estar relacionado à falta de percepção de risco ou ao fato de nunca ter recebido orientação por parte dos responsáveis pela empresa.

Os trabalhadores expostos a riscos constantes no ambiente de trabalho reconhecem que o uso de EPI pode conferir sensação de bem-estar, tranquilidade e equilíbrio durante a realização das atividades. Sabem, porém, que seu uso não elimina completamente o risco de exposição aos agentes térmicos. Além disso, identificam que alguns EPI interferem nas suas habilidades, dificultando a realização de procedimentos, o que contribui para a não utilização. ${ }^{16}$

O reconhecimento da importância do uso de EPI pelos trabalhadores e o emprego de práticas seguras reduzem significativamente 0 risco de acidentes ocupacionais. ${ }^{3,8}$ Contudo, o uso inadequado destes equipamentos de proteção pode ser considerado um dos aspectos que colaboram para ocorrência de acidentes de trabalho. Além disso, questionase a eficiência e a adequação dos EPI durante as atividades laborais, uma vez que os dispositivos utilizados nem sempre protegem os trabalhadores de acidentes e ainda podem aumentar a exposição, potencializando riscos e perigos de queimaduras. ${ }^{15}$

Cabe destacar que os riscos decorrentes da não utilização de EPI durante as atividades e do desconhecimento de sua importância podem ser subestimados pelos trabalhadores, os quais, sem proteção adequada, se expõem aos riscos de acidentes ocupacionais.

Autores ${ }^{3}$ referem que a adoção de práticas laborais seguras e o uso de EPI pelo trabalhador não estão relacionados apenas à sua subjetividade, mas, também, às condições de trabalho a ele proporcionadas. Ao analisar a adesão dos trabalhadores aos EPI, deve-se levar em consideração, além das condições de trabalho ${ }^{3}$, o contexto em que o trabalho é desenvolvido, a disponibilidade de informações e treinamento por parte dos empregadores e as concepções de saúde dos próprios trabalhadores, evitando assim a culpabilização destes indivíduos quando não aderirem ao uso dos equipamentos de proteção. ${ }^{16}$

O (re)conhecimento da importância do uso dos equipamentos de proteção durante a manipulação de agentes térmicos pode ser estimulado por meio de ações de prevenção e intervenção no ambiente de trabalho por parte da equipe de saúde, sobretudo de 


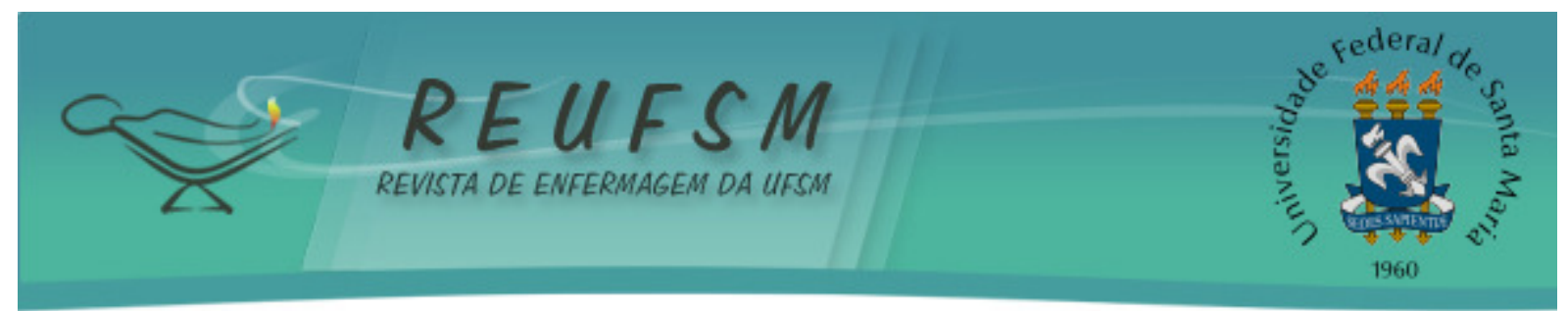

enfermagem. ${ }^{18}$ Perceber o enfermeiro como profissional de saúde com conhecimento técnico-científico, ético e político, permeado por múltiplos saberes de diferentes áreas, pode colocar este profissional como um membro importante da equipe de segurança e medicina do trabalho, para promover estratégias de prevenção de acidentes e de diversos outros aspectos que envolvem a saúde do trabalhador nos espaços laborais.

Neste contexto, o enfermeiro é um profissional fundamental para alicerçar ações de educação em saúde no âmbito das empresas, podendo atuar por meio de intervenções individuais ou coletivas, com base no diálogo e na troca de experiências, chamando os trabalhadores à reflexão acerca dos aspectos que afetam sua saúde e segurança no ambiente de trabalho. ${ }^{13}$ As ações de educação em saúde podem auxiliar a enfermagem na organização e no gerenciamento dos espaços de trabalho, ${ }^{2}$ em prol da proteção e segurança de inúmeros trabalhadores. ${ }^{3}$

\section{CONSIDERAÇÕES FINAIS}

Neste estudo, os trabalhadores reconheceram a manipulação de agentes térmicos como parte de suas atividades laborais e afirmaram estar cientes da necessidade de usar EPI adequados aos riscos no ambiente de trabalho. Entretanto, alguns expressaram a opção por não utilizá-los ou adaptá-los, contribuindo para sua maior exposição frente aos riscos de queimaduras.

Esta pesquisa permite concluir que as empresas em que os entrevistados mantinham um vínculo formal de trabalho necessitam investir na capacitação e treinamento dos trabalhadores para adequada utilização de EPI e EPC de forma a prevenir queimaduras e possibilitar um ambiente de trabalho mais seguro.

Compreende-se, como limitação, o fato desta investigação ter ocorrido após os acidentes de trabalho, o que pode ter influenciado as falas dos trabalhadores a respeito do uso de EPI, visto que o evento pode ter gerado um processo de reflexão sobre as circunstâncias que o envolveram. Ressalta-se ainda que, se a análise sobre a utilização dos equipamentos de proteção tivesse sido realizada em outro momento do processo de produção, possivelmente a visão dos trabalhadores seria distinta.

Com base nos resultados deste estudo, recomendam-se novas pesquisas que abordem a importância do uso de EPI para prevenção de queimaduras, contemplando maior número de sujeitos, e investigando a utilização destes equipamentos durante a realização do trabalho e não após registros de acidente. 0 desenvolvimento de pesquisas com outros olhares, envolvendo empregadores e trabalhadores que fazem parte do mesmo espaço e ritmo de trabalho, também permitiria propor novas estratégias individuais e coletivas para prevenção de queimaduras ocupacionais.

Um alerta especial dever ser dirigido à enfermagem no sentido de desenvolver, com a colaboração dos trabalhadores, ações educativas e preventivas que possam melhor conscientizá-los a respeito da importância do uso adequado de EPI e EPC para preservação de sua integridade física e psíquica.

\section{REFERÊNCIAS}

1. Organización Mundial de la Salud. Entornos laborales saludables: fundamentos y modelo de la OMS: contextualización, prácticas y literatura de apoyo. 2010:1-114.

2. Prochnow A, Magnago TSBS, Tavares JP, Beck CLC, Silva PM, Greco PBT. Perfil dos acidentes de trabalho publicados em estudos brasileiros. Rev Saúde (Santa Maria) [Internet]. 2011 janjun [acesso em 2013 maio 10];37(1):75-88. Disponível em:

http://cascavel.ufsm.br/revistas/ojs-2.2.2/index.php/revistasaude/article/view /2900/2060. 


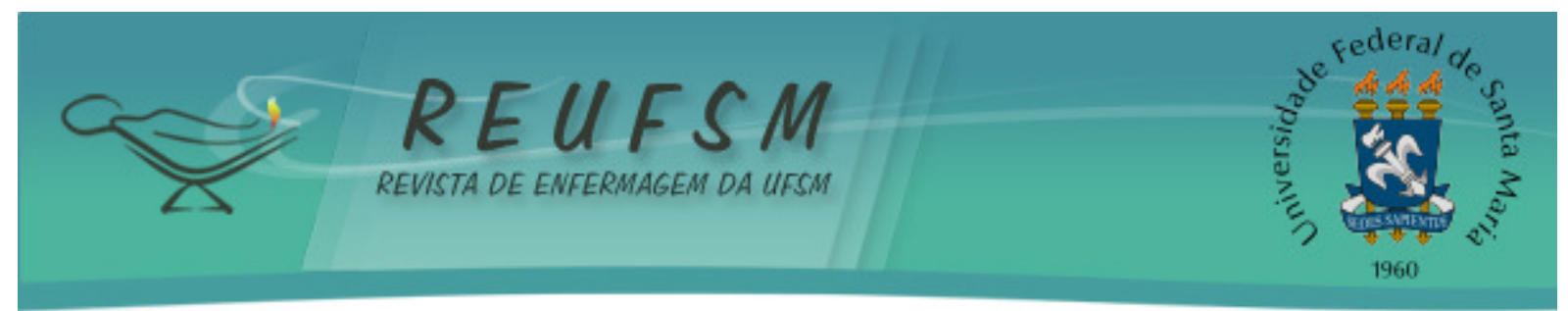

3. Prochnow A, Magnago TSBS, Tavares JP, Beck CLC, Silva RM, Ceron MDS, et al. Acidente de trabalho: uma revisão integrativa. Rev Enferm UFSM [Internet]. 2012 jan-abr [acesso em 2013 maio 10];2(1):156-64. Disponível em:

http://cascavel.ufsm.br/revistas/ojs-2.2.2/index.php/reufsm/article/view/2624.

4. Ministério do Trabalho e Emprego. Portaria SIT $n^{0}$ 194, de 07 de dezembro de 2010. Altera Norma regulamentadora $\mathrm{n}^{\circ}$ 6. Equipamento de Proteção Individual - EPI [Internet]. 2010 [acesso em 2013 jun 25]. Disponível em:

http: //portal.mte.gov.br/data/files/FF8080812DC56F8F012DCDAD35721F50/NR06\%20\%28atualizada\%29\%202010.pdf.

5. Fordyce TA, Kelsh M, Lu ET, Sahl JD, Yager JW. Thermal burn and electrical injuries among electric utility workers, 1995-2004. Burns. 2007;33(2):209-20.

6. Gawryszewski VP, Bernal RTI, Silva NN, Morais Neto OL, Silva MMA, Mascarenhas MDM, et al. Atendimentos decorrentes de queimaduras em serviços públicos de emergência no Brasil, 2009. Cad Saúde Pública [Internet]. 2012 abr [acesso em 2013 jul 17];28(4):629-40. Disponível em:

http://www.scielo.br/scielo.php?pid=s0102-311x2012000400003\&script=sci_arttext.

7. Silva EJ, Lima MG, Marziale MHP. O conceito de risco e os seus efeitos simbólicos nos acidentes com instrumentos perfurocortantes. Rev Bras Enferm [Internet]. 2012 set-out [acesso em 2013 jul 17];65(5):809-14. Disponível em:

http://www.scielo.br/scielo.php?pid=S0034-71672012000500014\&script=sci_arttext.

8. Luz FR, Loro MM, Zeitoune RCG, Kolankiewicz ACB, Rosanelli CSP. Riscos ocupacionais de uma indústria calçadista sob a ótica dos trabalhadores. Rev Bras Enferm [Internet]. 2013 jan-fev [acesso em 2013 jul 10]. Disponível em: http: / / www.scielo.br/scielo.php?pid=S0034-71672013000100010\&script=sci_arttext.

9. Brasil. Ministério da Saúde. Conselho Nacional de Saúde. Resolução $n^{\circ}$ 466, de 12 de dezembro de 2012 [Internet]. Brasília (DF): Ministério da Saúde; 2012 [acesso em 2013 jul 17]. Disponível em: http://conselho.saude.gov.br/resolucoes/2012/Res0466.pdf.

10. Bardin L. Análise de conteúdo. 1ạ ed. São Paulo: Edições 70; 2011. 279 p.

11. Montes SF, Barbosa MH, Sousa Neto AL. Aspectos clínicos e epidemiológicos de pacientes queimados internados em um hospital de ensino. Rev Esc Enferm USP [Internet]. 2011 [acesso em 2013 jun 25];45:369-73. Disponível em: http://www.scielo.br/pdf/reeusp/v45n2/v45n2a09.pdf.

12. Franco T, Druck G, Seligmann-Silva E. As novas relações de trabalho, o desgaste mental do trabalhador e os transtornos mentais no trabalho precarizado. Rev Bras Saúde Ocup [Internet]. 2010 [acesso em 2013 jun 25];35(122):229-48. Disponível em: http: / / www.fundacentro.gov.br/rbso/BancoAnexos/RBSO\%20122\%20Novas\%20rela\%C3\%A7\% C3\%B5es\%20de\%20trabalho.pdf.

13. Trindade LL, Krein C, Schuh MCC, Ferraz L, Amestoy SC, Adam EK. Trabalhadores da indústria têxtil: o labor e suas dores osteomusculares. J Nurs Health [Internet]. 2012 [acesso em 2013 out 30];2(2):377-87. Disponível em: http://www.ufpel.edu.br/revistas/index.php/enfermagemesaude/article/view/201/220.

14. Ministério do Trabalho e Emprego. Portaria SIT $n^{\circ} 247$, de 12 de julho de 2011. Altera NR 05 Comissão Interna de Prevenção de Acidentes [Internet]. 2011 [acesso em 2013 nov 3]. Disponível em: http://portal.mte.gov.br/data/files/8A7C812D311909DC0131678641482340/nr_05.pdf. 


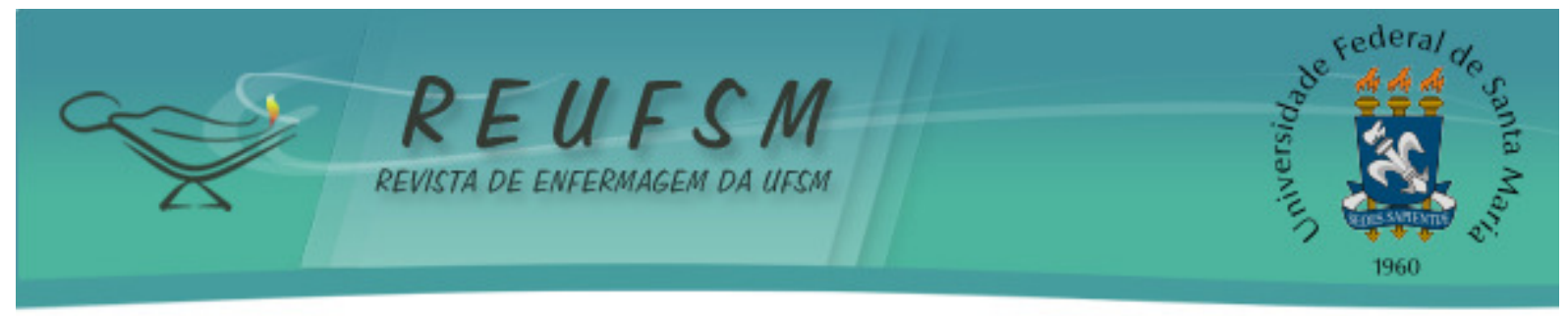

15. Espindola MCG, Fontana RT. Riscos ocupacionais e mecanismos de autocuidado do trabalhador de um centro de material e esterilização. Rev Gaúch Enferm [Internet]. 2012 mar [acesso em 2013 jun 15];33(1):116-23. Disponível em: http: / / www.scielo.br/scielo.php?pid=S1983-14472012000100016\&script=sci_arttext.

16. Neves HCC, Souza ACS, Medeiros M, Munari DB, Ribeiro LCM, Tipple AFV. Segurança dos trabalhadores de enfermagem e fatores determinantes para adesão aos equipamentos de proteção individual. Rev Latinoam Enferm [Internet]. 2011 [acesso em 2013 jun 15];19(2):[08 telas]. Disponível em: http://www.scielo.br/pdf/rlae/v19n2/pt_18.pdf.

17. Ministério do Trabalho e Emprego. Portaria GM n ${ }^{\circ}$ 598, de 07 de dezembro de 2004. Altera Norma regulamentadora $n^{\circ} 10$. Segurança em Instalações e Serviços em Eletricidade [Internet]. Brasília (DF): MTE; 2004 [acesso em 2013 jun 15]. Disponível em:

http://portal.mte.gov.br/data/files/8A7C812D308E216601310641F67629F4/nr_10.pdf.

18. Neuman B, Fawcett J. The Neuman Systems Model. 5th ed. Upper Saddle River, NJ: Pearson; 2011. 418 p.

Data de recebimento: 20/10/2013

Data de aceite: 13/01/2014

Contato com autor responsável: Maria Elena Echevarría-Guanilo

Endereço postal: Barão de Azevedo Machado 81/ 204. CEP: 96020-150. Pelotas, RS, Brasil.

E-mail: elena_meeg@hotmail.com 